\title{
Resúmenes de Tesis
}

\section{La dimensión publicitaria del Encomio de Helena de Gorgias'}

\author{
FELIPE MATÍAS NICASTRO²
}

En este trabajo me propongo analizar el Encomio de Helena buscando las maniobras que su autor ha realizado para hacer del texto una herramienta de promoción de sus clases de retórica. Así, en un primer apartado voy a caracterizar la inserción social de la sofística en la paideáa de la pólis ateniense de la última mitad del siglo $\mathrm{V}$ a.C. En un segundo apartado, veremos la relación que es posible establecer entre Gorgias y la tradición de la palabra poética de los llamados Maestros de verdad, con la intención de mostrar cómo, en varios momentos del texto, el orador de Leontinos aprovecha tanto el empuje que puede obtenerse al presentarse a la manera de un continuador de esa tradición, como el beneficio del distanciamiento o el sutil falseamiento de algunos aspectos de la misma. Finalmente, en un tercer apartado, explicaré desde qué coordenadas conceptuales Gorgias piensa el lógos y la persuasión en el Encomio, y cómo se inserta en ese panorama lo desarrollado en los apartados anteriores.

\section{Los primeros sofistas, sus estrategias para insertarse en la vida pública ateniense y sus detractores}

Con la crisis de las tiranías y el auge de las formas de gobierno democratizantes (siglo VI a.C.), el cambio de panorama político y social se abrió el camino a un nuevo tipo de enseñanza y a una nueva clase de profesional de la palabra que jugará un papel singular en las póleis. Alejándonos de la forma aristocrática más restringida de educación, primero ceñida a la enseñanza del arte de la guerra y luego a la del deporte, se empiezan a configurar formas de enseñanza ampliadas. Si bien no desaparecerá, el formato maestro-discípulo cederá su

I Tesina de Grado de la Licenciatura en Filosofía (Universidad Nacional de Rosario). Fecha de defensa: 18/03/20. Directora: Pilar Spangenberg. Tribunal: Anabel Hernández, Juan Manuel Viana y Rodrigo Sebastián Braicovich.

2 Universidad Nacional de Rosario (Rosario, Santa Fe, Argentina). fmnicastro@hotmail.com 
preeminencia a otra forma de enseñanza, simultánea, en la que un profesor enseñará a varios estudiantes a cambio de una suma de dinero (Marrou, 1976, pp. 45-48; de Romilly, 2010, p. 49). Esto va atado al auge sostenido de la escritura alfabética, que se vuelve un tema clave en la formación de los jóvenes griegos a partir del siglo V. Después de ir con el paidotríbes (maestro de atletismo), el citarista (maestro de canto y poesía) y el grammatistés (maestro de escritura), un joven ahora puede acceder a un curso con un sofista (Marrou, 1976, PP. 5I-56; de Romilly, 2010, pp. 45-46). Este personaje, controversial desde su nombre mismo, es un maestro itinerante que cobra por sus servicios. Hay distintas tarifas, según el tipo de enseñanza que busque el estudiante. Todos son bienvenidos a los encuentros publicitarios, a las epídeixis y a las charlas por un dracma. A diferencia de otros profesionales que enseñan una tékhne, como los artesanos, el sofista no enseña a otros a ser sofistas, sino a tener éxito en la vida de la ciudad (Platón, Protágoras, 3l|lb-3|2c); enseña una tékhne politiké (de Romilly, 20l0, pp. 48). Esto consistía, principalmente, en una formación retórica para ser un orador hábil, “capaz de persuadir, por medio de la palabra, a los jueces en el tribunal, a los consejeros en el Consejo, al pueblo en la Asamblea y en toda otra reunión en que se trate de asuntos públicos" (Platón, Gorgias, 452e, trad. Gredos). A través de una gran erudición literaria, y con la escritura y la mnemotécnica como herramientas, el sofista enseña a sus estudiantes a enfrentar lógos contra lógos en la plaza pública, en las asambleas y en las cortes, puesto que las formas democráticas ponen en el centro de su funcionamiento al manejo de la palabra. Saber cómo persuadir, argumentar e incluso dar vuelta un argumento desfavorable que se esgrime en contra son habilidades que adquieren una importancia capital en un sistema de gobierno en el que el derecho a la palabra y las incumbencias políticas se han expandido al grupo de los ciudadanos, es decir, los varones libres. En ese escenario nacen la retórica y la oratoria, dos artes que tienen en su mira no tanto la descripción de lo real a través de un lenguaje específico, cómo sería el caso de las primeras filosofías que buscaban explicar el kósmos de la phúsis, sino que apuntan a dominar lo verosímil y a saber capitalizar, a través de argumentos y argucias, las reacciones comunes de las personas (Marrou, 1976, Pp. 60-64). Para estas enseñanzas los sofistas se valían de un extenso conocimiento de la tradición poética, principalmente Homero y Hesíodo, pero también los líricos e incluso los trágicos contemporáneos (Platón, Protágoras, 338e-339a). En este sentido, la poesía se mantiene en el centro de la enseñanza sofística, lugar que ya detentaba, puesto que era tanto de la letra como de la tradición oral de los poetas de donde se extraían las enseñanzas que regían los valores de 
la vida cotidiana griega ${ }^{3}$. Sobre esos textos ejercían una tarea de crítica, comentarios didácticos, marcando errores gramaticales o señalando casos extraños en los usos de la lengua (80 DK A29-30; Navarre, 1900, pp. 40-4I). Más aún, su principal trabajo con las obras de la tradición poética era el estudio de sus metáforas, lugares comunes y estrategias sobre el ritmo de la composición. Sobre esta base los sofistas componían materiales modélicos para que sus estudiantes se ejercitaran (Navarre, 1900, Pp. 86- III). No obstante, el orador experimentado sabe que lejos de intentar forzar un modelo retórico idéntico con relación a todos los temas, hay que ser sensible a la especificidad de cada escena retórica, saber detectar las reglas de cada ámbito para poder sumergirse de lleno en él y conquistar al auditorio desde adentro. Los sofistas y los oradores, como los profesionales y los artesanos, están atentos a la oportunidad o la circunstancia propicia (kairós) (Vernant, 1985, p. 269 n. 75; Marrou, 1976, pp. 50 y 67; Galí, 1999, p. 191).

Ahora bien, no por por el hecho de que hayan tenido éxito hay que considerar que los sofistas tuvieron las cosas sencillas. Antes bien debieron crearse un lugar entre quienes ejercían la paideía de la época, sortear los argumentos de sus detractores, posicionarse entre los maestros existentes y construirse un auditorio interesado en lo que venían a ofrecer (Marrou, 1976, pp. 59-60; de Romilly, 2010, pp. 48 y 55). En principio, tenían que afrontar el hecho adverso de ser extranjeros en Atenas. En efecto, los grandes sofistas de la primera generación eran, en su gran mayoría, extranjeros. Muchos de ellos llegaban allí desde sus tierras por misiones políticas y aprovechaban para hacer sus negocios personales dando clases de oratoria (Guthrie, 2003, p. 50). Para atraer nuevos alumnos o impresionar a los gobiernos de turno para que los contraten para dar discursos públicos, los sofistas debían recurrir a toda una serie de estrategias publicitarias (Navarre, 1900, pp. 31-66; Marrou, 1976, p. 59; Guthrie, 2003, pp. 5 I-53), como dar charlas de difusión baratas o gratuitas, las llamadas epídeixeis, que funcionaban como una muestra, accesible a cualquiera, de lo que se podía aprender con el maestro en caso de tener el dinero para costear el curso completo. Se trataba de presentaciones públicas - a menudo con premio - en las que el orador daba rienda suelta a su ingenio y podía discurrir frente a un gran auditorio — por ejemplo los juegos panhelénicoscon tema libre, aunque generalmente tenía temáticas míticas o didácticas. Otras veces la epídeixis consistía en la defensa de una tesis polémica (Marrou, 1976, pp. 62-63). Otra estrategia afín era llevar a los alumnos ya reclutados de gira, para que el estudiante ya avanzado

3 Esta efectiva preponderancia de la poesía en la paideía es lo que explica el énfasis que pondrá Platón en aclarar lo indeseable que le resulta ese material didáctico en su pólis ideal. 
FELIPE MATÍAS NICASTRO

La dimensión publicitaria del Encomio de Helena de Gorgias

Resúmenes de Tesis

diera fe de la capacidad y la veracidad de lo promocionado por el sofista mostrando sus habilidades de oratoria (Platón, Protágoras, 314e-316a). Además, se servían de la composición de los manuales escritos llamados "tékhnai", los cuales consistían en consideraciones teóricas sobre oratoria y gramática, aunque principalmente incluían modelos de discursos en los que el maestro enseñaba estrategias que luego era posible extrapolar a otras situaciones o casos (Guthrie, 2003, p. 54, n. 45). No serían discursos destinados solamente a ser memorizados, sino casos paradigmáticos sobre la base de los cuales ver en acción lo que enseñaba la teoría; es decir, se trataba de textos modélicos que servían para luego armar discursos persuasivos que tenían por finalidad situaciones concretas reales. Así, pues, estos diversos modos de publicidad le permitían al sofista mezclar su capacidad oratoria con su calidad argumentativa y sus preocupaciones teóricas.

Por otra parte, el sofista, como profesional de la palabra que era, debía abrirse paso en un contexto que no le era del todo favorable. En principio, debido a que, en distintos momentos, fue variando la aprobación y la jerarquía social de aquellos que se dedicaban a las tékhnai y los trabajos manuales (Coarelli, 1980: Xl; Vernant, 1985: 247-249, 258 n. 26, 262, 297 n. 42). En general, trabajar en una profesión era alejarse del ideal de hombre griego, que era el varón autónomo, que dedicaba su libertad a la vida política y al entrenamiento físico ${ }^{4}$. Frente a este panorama desfavorable los sofistas no estaban solos. No fueron los únicos que pensaron estrategias publicitarias para insertarse en el mundo de la pólis ${ }^{5}$. Otros ejemplos los encontramos también en los ámbitos de los médicos (Roth, 200I, pp. 4-7; Vernant, 1985, PP. 292 n. 28), los poetas (Galí, 1999, pp. 149-157), los escultores y pintores (Coarelli, 1980, pp. XXII-XXIII). Cada uno de ellos, a su modo, tuvo que abrirse paso entre dos escollos al mismo tiempo: por un lado, las formas sacralizadas de sus artes, y por otro lado, la baja estima en la que se tenía toda tékhne. El sofista, por su parte, tenía que abrirse lugar entre los maestros ya existentes (paidotríbes, citarista y grammatistés) y la tradición de los oradores inspirados (los antiguos aedos). En este sentido, entrar en el terreno de las tékhnai es ya dar un paso para alejarse del mundo divino (Vernant, 1985, p. 259) ${ }^{6}$. También transformar en mercancía la

4 Vernant (1985, p. 26I, n. 4I) señala que no hay que confundir esto con la idea decimonónica de que los griegos priorizaban la intelectualidad por sobre la acción. Esto también se ve en la historia de la paideía griega, fuertemente marcada por la presencia del deporte, y que sólo tardíamente toma un carácter más libresco.

5 Por otra parte, es la pólis es la que permite una definición positiva de las tékhnai (Vernant, 1985, p. 263). 
palabra y la paideía era un gesto sumamente disruptivo. ${ }^{7}$ Cobrar por enseñarle a un ciudadano a ser exitoso en la vida pública era algo que los sofistas hacían (Platón, Menón, 9la-92d), pero no pasaba desapercibido para los atenienses (Vernant, 1985, p. 273), puesto que ponía contra las cuerdas a las familias nobles que detentaban un linaje cargado de grandes dirigentes y reformadores como si fuera una credencial habilitante para continuar ejerciendo los cargos. Es una faceta en la gran disputa entre phúsis y nómos, entre lo que es por naturaleza y lo que es por costumbre o educación. Que la areté se vuelva enseñable significa que deja de ser el privilegio de una casta y pasa a ser el resultado de un aprendizaje al que se puede acceder si se tienen los medios necesarios (Guthrie, 2003, p. 36).

Así, pues, el sofista tiene una reputación que, cuando menos, resulta ambigua. Esto ya se ve en el vocabulario mismo de época, en la cual sophistés deja de designar a alguien sabio o habilidoso, o incluso alguien versado en poesía, y pasa a tener una connotación negativa (Guthrie, 2003, pp. 39-44). Ahora bien, es en este contexto en el que hay que considerar fue producido el Encomio de Helena. Se trata, entonces, de la producción de un profesional de la palabra, un extranjero, un maestro itinerante de oratoria que quiere hacerse un lugar en la paideía de la época, que necesita publicitar su enseñanza, resaltar su importancia y pertinencia para la coyuntura política, y demostrar sus habilidades, logrando llamar la atención del público para convertirlo no sólo en su auditorio, sino también en su clientela.

\section{2. "Cosas demasiado conocidas"}

En el capítulo dedicado al Encomio de Helena en su clásica obra I Sofisti, Mario Untersteiner pasa más o menos de largo los primeros cinco parágrafos del texto aduciendo que constituyen cosas "demasiado conocidas y que tienen poco interés filosófico" (1954: 103) como para abundar en comentarios sobre ellas. Sin embargo, ya desde el comienzo el Encomio ofrece elementos que deben ser revisados con detenimiento, puesto que no son ociosos a la hora de contribuir a la economía persuasiva del texto. Comencemos por el §I. Allí Gorgias escribe:

6 No obstante, en el vasto mundo de las representaciones divinas del panteón griego, también hay divinidades asociadas a las tékhnai (Vernant, 1985, pp. 242-252).

7 Simónides de Ceos es un caso emblemático de esta actitud.

8 Guthrie (2003, p. 48) menciona ejemplos en los que el sofista es peor visto, al pretender cobrar por enseñar areté, que otros profesionales que también cobran por sus enseñanzas: Platón, Menón 9ld y Protágoras 3 I Ic (escultores); Heródoto, III, I3I (médicos); Aristóteles, Retórica, I405b24 (poetas). 
FELIPE MATÍAS NICASTRO

La dimensión publicitaria del Encomio de Helena de Gorgias

Resúmenes de Tesis

es necesario honrar con elogio lo que es digno de elogio pero cubrir de censura lo que es indigno. Pues igual error y desconocimiento es censurar lo elogiable que elogiar lo censurable. ${ }^{9}$

En esas líneas vemos que Gorgias se adjudica el deber de continuar una tarea que tradicionalmente era de la incumbencia de los poetas: la alabanza y la desaprobación. Se infiere aquí, entonces, un gesto de connivencia con esa tradición. Ahora bien, inmediatamente después, en el §2, Gorgias escribe:

Por eso, corresponde a un mismo hombre decir correctamente lo debido y contradecir a los que censuran a Helena, mujer sobre la cual llegó a ser unísona y unánime la creencia [pístis] de los poetas, que saben por lo que escucharon, y la fama de su nombre, que llegó a ser recuerdo de desgracias.

En este otro pasaje, en cambio, lo que se filtra, en oposición al primero, es una actitud poco respetuosa a la tradición de la palabra poética. En efecto, hablar de una refutación de la pístis, de la credibilidad que media entre las afirmaciones de los poetas y su auditorio, es tomar distancia de la tradición y efectuar, en simultáneo, una interpretación y una crítica de los mecanismos de validación y los privilegios de la palabra poética. (Melero Bellido, 1997, p. 14I, n. 131) Por lo tanto, encontramos, ya desde el comienzo del texto, cierta tensión entre dos actitudes aparentemente contrapuestas: por un lado, el cuestionamiento del juicio que sedimentó la tradición sobre Helena y, por otro lado, la prolongación de una práctica propia de la palabra poética tradicional: la alabanza y la desaprobación. Para hacer sentido de estas diversas actitudes que mantiene Gorgias frente a los poetas y sus funciones, conviene que nos adentremos en dos cuestiones fundamentales: por un lado, qué características adjudicamos a la palabra poética mágico-religiosa y, por otro lado, qué entendemos por credibilidad (pístis) en este terreno.

Respecto a lo primero, desde los ineludibles análisis de Marcel Detienne sobre este tema, sabemos que la palabra del poeta inspirado por los dioses se fundaba, por un lado, en el privilegio de una función social en el seno de las sociedades micénicas (s. XII a.C), y, por otro, sobre un don de memoria-omnisciencia que le otorgaban las Musas (Detienne, 1981, PP. 32, 37-38, 66, 68-69) . Este don de memoria-omnisciencia le garantizaba al poeta, a su vez, dos facultades convergentes: de una parte, su capacidad para realizar cosas, su eficacia; y por otra, el acceso a la dimensión divina de la realidad. De tipo asertórico, esta palabra se identificaba

9 Citaremos siempre la traducción del Encomio de Helena de Chialva et. al., 2013. 
con la Verdad (Alétheia) y, por ello mismo, en tanto que trascendía el tiempo de los hombres, podía prescindir de su aval; es decir: nadie la ponía a prueba y nadie la ponía en duda. Así, según Detienne, "en ningún momento busca la palabra del poeta el acuerdo de los auditores, el asentimiento del grupo social" (198I, p. 66). Por lo demás, la alétheia que esta palabra protagonizaba se articulaba sobre una Memoria (mnemosyne) que no responde al esquema temporal profano (Vernant, 1985, pp. 95, 109-110 y 116, n. 98), sino que se vincula con la intemporalidad de lo divino, "el tiempo de los dioses que son siempre" (Galí, 1999, p. 35), donde conviven en simultáneo aquellos aspectos que nosotros no podemos dejar de separar y llamar "pasado", "presente” y "futuro". Además, a esta Memoria-Verdad no se le opone lo falso (pseudos) sino el olvido (lethê), lo cual resulta más comprensible a la luz las dos funciones principales de esta palabra poético-religiosa; a saber: la alabanza y la desaprobación. Ahora bien, conviene no confundir estas dos funciones con juicios personales sobre un tema (Detienne, 198I, p. 66). En cambio, la alabanza y la desaprobación son potencias religiosas. La primera, la alabanza, se vinculaba con la Verdad y la Memoria, con mantener cercana y viva en la palabra una hazaña o un personaje digno de ser cantado y recordado. La desaprobación, en cambio, se vinculaba con el Olvido y el Silencio, con el dejar que lo deplorable cayera, por su propio peso, en los rincones alejados y oscuros del discurso, e incluso más allá, por fuera de él. Por lo demás, ambas funciones responden a la lógica mítica de los opuestos complementarios (Detienne, 198I, pp. 32, n.63 y 83-84; Vernant, 1985, pp. 339, 34I y 343-345). Así, en este contexto mágico-religioso, aunque la verdad (alétheia) se opone al olvido (Lethe), estas fuerzas no están separadas una de la otra, y la palabra eficaz y verdadera de los "Maestros de Verdad" convive con las potencias del olvido, revelándose fundamentalmente ambigua (Detienne, 1981, Pp. 69, 73, 75, 78 y 83-84). Más aún, las dulces palabras que cantan los aedos inspirados por el don de videncia-memoria de las Musas, hijas de Mnemosyne, también hacen olvidar las desgracias y bloquean los recuerdos perjudiciales ${ }^{10}$. Incluso las mismas Musas reconocen su facilidad para la ambigüedad: "Sabemos decir muchas mentiras con apariencia de verdades; y sabemos, cuando queremos, proclamar la verdad" ". Así, hay que notar otro rasgo clave de esta ambigüedad: el arcaico maestro de verdad también es un maestro de engaño (apáte), y este engaño que ejerce es positivamente valorado.

10 Hesíodo, Teogonía, 95-105.

II Hesíodo, Teogonía, vv. 27-29. 
En cuanto a la credibilidad (pístis), en los textos de la tradición poética señala dos tipos de actitudes vinculadas entre sí: por un lado, indica la confianza mutua y recíproca entre los hombres (por ejemplo, los juramentos), pero, por otro lado, pístis señala la confianza unilateral de los hombres en los dioses, la fe en su palabra, y también la fe en la palabra oracular y la confianza en el don de las Musas (Detienne, 198I, p. 68; Vernant, 1985, p. 345, n. 27). Podría decirse que este segundo sentido de pístis apunta a la fe en la eficacia de una palabra mágicoreligiosa. Sin embargo, este tipo de fe no debe confundirse con una conducta psicológica vinculada a la intimidad de la voluntad; antes bien, pistis es el acuerdo imperioso al que obliga toda palabra eficaz, es decir, es una consecuencia persuasiva de la potencia que aquí adquiere alétheia (Vernant, 1985, p. 90; Detienne, 198I, p. 22, n. 6 y 68-69). Esto da indicios, también, del fuerte vínculo entre credibilidad y persuasión (pistis y peithô) sobre el que volveré más adelante.

De modo tal que, según lo dicho hasta aquí, la palabra poética del maestro de verdad arcaico no buscaba el aval del auditorio, puesto que su condición inspirada y su eficacia misma para instalar una realidad eran, a la vez, la prenda de su verdad y de su potencia persuasiva, esto es, la condición misma de su credibilidad. En este sentido, que la alabanza y la desaprobación constituyeran sus dos principales formas de ejercicio nos revela que es en discursos de esa índole donde mejor era posible alcanzar esa potencia persuasiva, lo cual nos devuelve, justamente, a los temas que mencionábamos como puestos en tensión por Gorgias en la estructura misma de su Encomio.

Veamos entonces si podemos distinguir las maniobras que Gorgias realiza en los parágrafos citados y cómo aportan a la publicidad de sus enseñanzas de oratoria. Primera maniobra: al pretender refutar la palabra de los poetas (EH §2), el orador pone en duda lo que solía ser incuestionable. Segunda maniobra, correlativa a la primera: al desnudar su anclaje en la pistis (EH §2), Gorgias deteriora los efectos de la palabra mágico-religiosa, entendida ésta como vinculada a cierta compulsión persuasiva. Tercera maniobra: el orador, a la vez que ataca la palabra mágico-religiosa, se propone llevar a cabo las dos tareas consustanciales a este tipo de palabra: el elogio de lo digno de elogio y el vituperio de lo indigno de elogio (EH §I). De este modo, el rhétor establece, desde el comienzo mismo del escrito, un juego ambiguo con los elementos tradicionales: en este caso, y en vista de sus propósitos persuasivos vinculados a la publicidad de sus clases, Gorgias sabe que necesita alcanzar ciertos efectos que, si no logran ser iguales, sí deben ser, cuando menos, similares a los que lograba la palabra eficaz de los poetas. Para llevar a cabo tal propósito, tomará de ella lo que le conviene, a saber, la práctica 
FELIPE MATÍAS NICASTRO

La dimensión publicitaria del Encomio de Helena de Gorgias

Resúmenes de Tesis

de la alabanza y la desaprobación; $y$, a su vez, atacará lo que le estorba, que, en este caso, es la falta de atención que la palabra poética tradicional prestaba al auditorio, al cual no necesitaba recurrir para ser considerada una palabra eficaz. Sin embargo, entre la época del auge de la palabra poética mágico-religiosa y el siglo $\mathrm{V}$, la dinámica de la vida social ha cambiado. En el contexto político en el que Gorgias se desempeña hay que convencer al auditorio para lograr los efectos que desean llevar a cabo con el discurso. La inmediatez de la palabra eficaz del poeta que era maestro de verdad y engaño se ve atravesada por las formas democratizadas de las póleis, donde es la asamblea de los hombres libres en conjunto la que decide el destino de su vida política mediante el voto directo, apoyando tal o cual discurso que motiva tal o cual decisión o ley.

\section{Gorgias conquista los poderes de la poesía para el lógos en general.}

Por otra parte, en el Encomio Gorgias pone en primer plano el rol del engaño (apáte) y el deleite (térpsis) en la producción de efectos persuasivos, esto es, en la manipulación de las creencias (pístis) y opiniones (dóxa) del auditorio. Sin embargo, creo que lo que resulta muy particular en este texto de Gorgias es que las tesis que el autor sostiene no se enuncian como tales, sino como lecturas o como críticas a terceros, lo cual implica un ejercicio de lectura bastante arduo. En efecto, cuando un discurso anclado en el engaño es elaborado con fines persuasivos, y además se da como tema el engaño que implican los discursos persuasivos (EH §8-14), la relación entre forma y contenido del discurso provoca que la línea que separa la denuncia de la postulación se difumine, permitiendo y ocasionando deslizamientos de un lado al otro de la misma.

Con esto en mente, el Encomio de Helena no puede tomarse como lo que parece ni a primera ni a segunda vista. Es decir, considerado desde la perspectiva de una persuasión que opta por el engaño, el texto no puede tomarse solamente como un elogio o una defensa de la infame mujer involucrada en la guerra de Troya, ni tampoco, como a veces parece suficiente decir, a la manera de un mero elogio del lógos (Cassin, 2008, pp. 118-119). Más bien, en términos de lo que me he propuesto rastrear aquí, encuentro necesario pensar que con este texto Gorgias tenía que hacer frente a diversos obstáculos que se le presentaban en su camino profesional: por una parte, la mala imagen que le daba, frente a los representantes del orden conservador, el cobrar por sus enseñanzas; además la concepción degradada de las tékhnai que tenían ciertas capas sociales hegemónicas de la época; también la competencia que 
FELIPE MATÍAS NICASTRO

La dimensión publicitaria del Encomio de Helena de Gorgias

Resúmenes de Tesis

representaban los otros maestros que formaban a los jóvenes; $y$, finalmente, el ataque de sus detractores (ya sea por su rol político o por sus preferencias teóricas). Este complejo panorama también permite entender la necesidad del sofista de vampirizarle recursos a la tradición poética, cuyo lugar de prestigio en la paideía podía resultar un modelo a la hora de aspirar a ganarse un lugar destacado en ese ámbito. Enfrentarse y sustraerle recursos a la poesía era una buena manera de terminar de bajarla de su antiguo pedestal mágico-religioso y, a su vez, de poner en pie de igualdad, junto a las demás tékhnai, su tékhne rhetoriké (de Romilly, 1973, pp. 155-162).

De modo tal que el Encomio de Helena explota de principio a fin un juego entre distintos niveles de enunciación que van desde un elogio del lógos que se desliza detrás de la defensa de la dudosamente infame Helena, a la construcción de una teoría de un lógos abocado al engaño y a la persuasión que se formula a sí mismo a través de denuncias y críticas a prácticas de persuasión engañosa (EH §I4). Por eso, las críticas que Gorgias lleva a cabo contra la tradición poética no se dejan subrayar sin caer en señalamientos relativos a las prolongaciones que el autor realiza de temas y prácticas concernientes a esa misma tradición. En este sentido, el análisis que Gorgias hace de las prácticas discursivas de los poetas tradicionales se trenza con los argumentos engañosos que el orador elabora para ordenar y desarrollar el texto, volviendo indistinguible la crítica de la preferencia conceptual.

\section{Conclusiones}

Esclarecido ya el recorrido general del Encomio y repuesto el contexto histórico del mismo, resulta evidente que la tensión entre Gorgias y los poetas tradicionales tenía una finalidad pragmática para aquél. No se trataba de enfrentarse con la tradición poética por el honor de Helena, sino de conquistar un espacio para la sofística y la retórica en la paideía del siglo V. Más aún, se trataba de desmontar los recursos persuasivos y psicagógicos de esa tradición poética para reclamarlos como atributos del lógos en general, es decir, para la prosa y la oratoria. Todos fueron incluidos en el juego gorgiano, desde los poetas hasta los filósofos, pasando por los oradores forenses y los terapeutas. Cada mención de Gorgias a un tipo de palabra que circulaba en su época, o que incluso era venerada ya desde otras épocas, tiene por objetivo incrementar el campo de acción e influencia de la retórica. Todos los discursos caen bajo el dominio de la tékhne rhetoriké, puesto que el lógos es uno, aunque se lo presente de distintas maneras, o haya que amoldarse a distintas reglas retóricas según el escenario en el 
FELIPE MATÍAS NICASTRO

La dimensión publicitaria del Encomio de Helena de Gorgias

Resúmenes de Tesis

que toque tener que generar persuasión. La poesía, en este sentido, ha sido el blanco más tematizado por el sofista puesto que era el tipo de palabra más respetada por los griegos. Conquistarle terreno y recursos a la tradición poética era un movimiento osado que Gorgias tenía que hacer para llevar adelante su plan de ubicarse en la paideía vigente. Es por eso también que la poesía se vuelve el objeto de un ejercicio sofístico, ya que Gorgias a la vez la ataca y la elogia, la usa y la desarma.

\section{Referencias}

Cassin, B. (2008). El efecto sofístico. Fondo de Cultura Económica.

Chialva, I., et al. (2013). Gorgias, Encomio de Helena. Ediciones UNL.

Coarelli, F. (ed.) (1980). Artisti e artigiani in Grecia. Guida storica e critica. Laterza.

de Romilly, J. (1973). Gorgias et le pouvoir de la poésie. Journal of Hellenistic Studies, 93, I55162.

de Romilly, J. (2010). Los grandes sofistas de la Atenas de Pericles. Gredos.

Detienne, M. (198I). Los maestros de verdad en la Grecia arcaica. Taurus.

Galí, N., (1999). Poesía silenciosa, pintura que habla. El Acantilado.

Guthrie, W.K.C. (2003). Historia de la filosofía griega (Vol. 3). Gredos.

Hesíodo. (1995). Teogonía. Trabajos y días. Escudo. Planeta DeAgostini.

Marrou, H.-I. (1976). Historia de la educación en la Antigüedad. EUDEBA.

Melero Bellido, A. (ed.) (1997). Sofistas: Testimonios y fragmentos. Planeta DeAgostini.

Navarre, O. (1900). Essai sur la Rhetorique grecque avant Aristote. Hachette.

Platón. (2007). Diálogos. Madrid.

Roth, A. (200I). "Rhetoric and Faith in the Hippocratic Philosophy of Medicine". En Krieger,

W. H. (Ed.), Science at the Frontiers: Perspectives on the History and Philosophy of Science (pp. 3-16). Plymouth Lexintong Books.

Untersteiner, M. (1954). The sophists. Basil Blackwell.

Vernant, J.-P. (1985). Mito y pensamiento en la Grecia antigua. Ariel. 